\title{
Exchange-Biased Magnetoresistive Elements with Oxide Antiferromagnetic Thin Films
}

\author{
Katsuro WATANABE ${ }^{1}$, Shigeru TADOKORO ${ }^{1}$, Takashi KAWABE ${ }^{1}$, Moriaki FUYAMA ${ }^{1}$ \\ Hiroshi FUKUI ${ }^{2}$, and Shinji NARISHIGE ${ }^{2}$
}

1) Central Research Laboratory, Hitachi Ltd., 7-1-1 Omika-cho, Hitachi, Ibaraki 319-12 Japan

2) Data Storage \& Retrieval Systems Division, Hitachi Ltd., 2880 Kozu, Odawara, Kanagawa 256 Japan

\begin{abstract}
The corrosion resistance of an oxide antiferromagnetic NiO film and the exchange coupling between this film and $\mathrm{Ni}_{81} \mathrm{Fe}_{19}$ film were investigated for application to MR heads. The corrosion resistance of NiO film was superior to that of FeMn and $\mathrm{Ni}_{81} \mathrm{Fe}_{19}$ films. Bilayered $40 \mathrm{~nm} \mathrm{Ni} 81 \mathrm{Fe}_{19} / 100 \mathrm{~nm}$ NiO films had an exchange coupling field of about 20 Oe and blocking temperature of about $200{ }^{\circ} \mathrm{C}$. An unshielded MR element was fabricated, on both sides of which patterned NiO films were placed. The magnetization pattern of $\mathrm{Ni}_{81} \mathrm{Fe}_{19}$ film which exhibited exchange coupling with the patterned $\mathrm{NiO}$ films on both sides showed a single domain state. Distortion associated with Barkhausen jumps was not observed in the MR response for the unshielded MR element nor in the reproductive waveform for a shielded MR head either.
\end{abstract}

\section{INTRODUCTION}

Areal density of magnetic recordings has become steadily higher in response to trends that magnetic rigid disk drives are being miniaturized and storage capacities are becoming larger. Intensive research has been carried out for development of a magnetoresistive (MR) head for a read element, because the MR head has a large seproductive signal voltage even under low relative speed between the head and recording medium. The MR head needs suppression of the Barkhausen noise associated with irreversible motion of magnetic domain walls in an MR stripe. An effective suppression method is realizing a single domain state in the MR stripe by inducing a unidirectional anisotropy, [1] and making use of exchange coupling between an MR stripe and an antiferromagnetic material. In particular, exchange coupling between $\mathrm{NiFe}$ films, Which are widely used as MR material, and FeMn films has been investigated in detail.[2]-[7] Because FeMn films have poor corrosion resistance, some research on other antiferromagnetic films has also been done. [5],[8]

We have used an oxide antiferromagnetic NiO film for the antiferromagnetic material because of its good corrosion resistance and high Neel temperature. [9]-[11] In this report, we describe typical exchange coupling between $\mathrm{Ni}_{81} \mathrm{Fe}_{19}$ films and oxide antiferromagnetic $\mathrm{NiO}$ films and the MR element with $\mathrm{NiO}$ films.

\section{EXPERIMENT}

The $\mathrm{NiO}$ and $\mathrm{Ni}_{81} \mathrm{Fe}_{19}$ films were deposited on glass substrates with an $\mathrm{rf}$ diode magnetron sputtering system having two targets, and the deposition of the exchange coupled films was done sequentially. A dc magnetic field of 40 Oe was applied in the plane of the substrate in order to induce uniaxial anisotropy to the $\mathrm{Ni}_{81} \mathrm{Fe}_{19}$ film and define the unidirectional anisotropy axis in the exchanged coupled films. After evacuating below $4 \times 10^{-7}$ Torr, the film deposition was typically performed at an argon pressure of $0.6 \mathrm{mT}$ Torr for the $\mathrm{Ni}_{81} \mathrm{Fe}_{19}$ film, and 0.6 and 3 mTorr for the NiO film.
Corrosion resistance was examined for the difference in film thickness between before and after immersing in test solutions with various hydrogen ion concentrations $(\mathrm{pH})$ at $80^{\circ} \mathrm{C}$ for $3 \mathrm{~h}$. The $\mathrm{pH}$ of test solutions were controlled by adding hydrochloric acid or sodium hydroxide to neutral water.

For the exchange coupled films, the magnetic properties were measured after annealing at $250{ }^{\circ} \mathrm{C}$ for 30 min in vacuum in a dc magnetic field of $40 \mathrm{Oe}$. The exchange coupling field $\left(\mathrm{H}_{\mathrm{e}}\right)$ was measured by a $\mathrm{B}-\mathrm{H}$ loop tracer. The blocking temperature $\left(T_{B}\right)$, defined as the temperature at which $\mathrm{H}_{\mathrm{e}}$ disappears, was investigated with a Kerr effect apparatus, the temperature variation of $\mathrm{H}_{e}$ was observed while heating the exchange coupled films in air up to $220^{\circ} \mathrm{C}$.

\section{RESULTS}

\section{A. Corrosion Resistance}

Corrosion rate, which is the etched thickness per $1 \mathrm{~h}$, is used for evaluation of corrosion resistance. Figure 1 shows the corrosion rates of two kinds of antiferromagnetic films, $\mathrm{NiO}$ and $\mathrm{FeMn}$, along with $\mathrm{Ni}_{81} \mathrm{Fe}_{19}$ film for a reference. The FeMn film has poorer corrosion resistance than $\mathrm{Ni}_{81} \mathrm{Fe}_{19}$ and $\mathrm{NiO}$ films. Above $\mathrm{pH} 4$, the corrosion rate of $\mathrm{NiO}$ film is nearly equal to that of $\mathrm{Ni}_{81} \mathrm{Fe}_{19}$ film, while at $\mathrm{pH} 2$ the rate of $\mathrm{NiO}$ film is much smaller than that of $\mathrm{Ni}_{81} \mathrm{Fe}_{19}$ film. Therefore the $\mathrm{NiO}$ film has excellent corrosion resistance, especially under acidic conditions.

\section{B Magnetic Properties of Exchange Coupled Films}

The typical B-H loop of a bilayered $\mathrm{Ni}_{81} \mathrm{Fe}_{19} / \mathrm{NiO}$ film, a $40 \mathrm{~nm}$ thick $\mathrm{Ni}_{81} \mathrm{Fe}_{19}$ film laminated on a $100 \mathrm{~nm}$ $\mathrm{NiO}$ film which was deposited at $0.6 \mathrm{mTorr}$, is shown in Figure 2. The easy direction B-H loop shifts by 22.9 Oe, which is defined as $\mathrm{H}_{e}$, and exhibits fair squareness and a coersive force of $12.4 \mathrm{Oe}$. The hard direction loop indicates that exchange coupling effect causes the magnetization in $\mathrm{Ni}_{81} \mathrm{Fe}_{19}$ to be hard to rotate as compared 


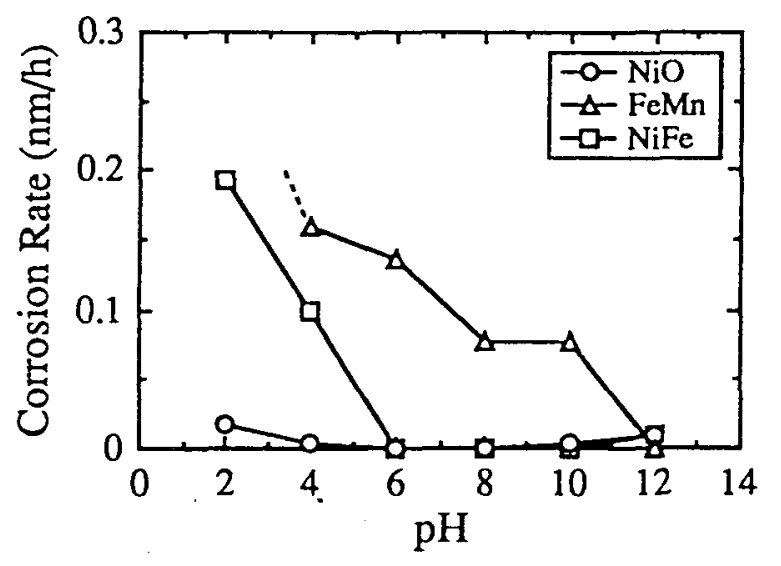

Fig.1 Corrosion characteristic of NiO, FeMn and NiFe films.
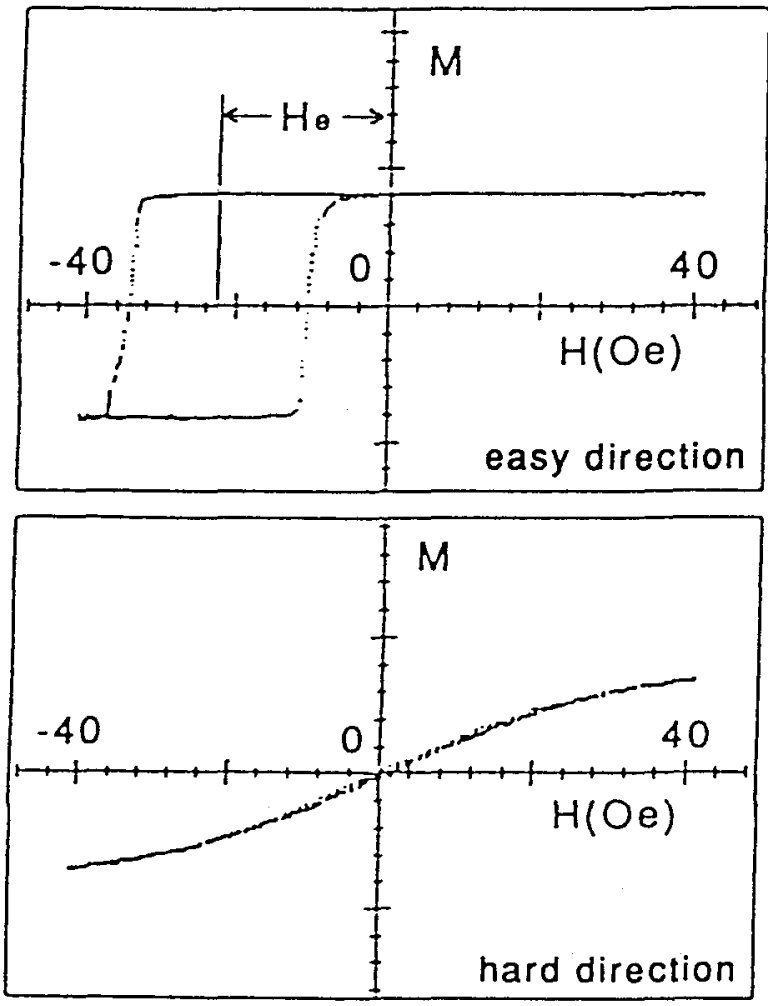

Fig.2 Typical B-H loop for bilayered $40 \mathrm{~nm} \mathrm{Ni}{ }_{81} \mathrm{Fe}_{19} / 100 \mathrm{~nm}$ NiO films.

with the saturating field of about 5 Oe for typical $\mathrm{Ni}_{81} \mathrm{Fe}_{19}$ films. Bilayered $100 \mathrm{~nm} \mathrm{NiO} / 40 \mathrm{~nm} \mathrm{Ni} 81 \mathrm{Fe}_{19}$ films have $\mathrm{H}_{e}$ of about $14 \mathrm{Oe}$ and this value is smaller than that of bilayered $\mathrm{Ni}_{81} \mathrm{Fe}_{19} / \mathrm{NiO}$ films. The poor quality of the initial growth layer of $\mathrm{NiO}$ film can be attributed to deterioration in $\mathrm{H}_{e} . \mathrm{H}_{e}$ of about $20 \mathrm{Oe}$ is obtained for $\mathrm{NiO}$ films above $50 \mathrm{~nm}$ thick and this value is almost the same as that of FeMn / NiFe reported previously. [1]-[7]

The temperature dependence of $\mathrm{H}_{\mathrm{e}}$ of bilayered $40 \mathrm{~nm}$ $\mathrm{Ni}_{81} \mathrm{Fe}_{19} / 100 \mathrm{~nm} \mathrm{NiO}$ films, in which $\mathrm{NiO}$ films were deposited at different argon pressures, 0.6 and $3 \mathrm{mTorr}$, is shown in Figure 3. For comparison, dependence of bilayered $20 \mathrm{~nm} \mathrm{FeMn} / 40 \mathrm{~nm} \mathrm{Ni}{ }_{1} \mathrm{Fe}_{19}$ films ${ }^{[12]}$ is also

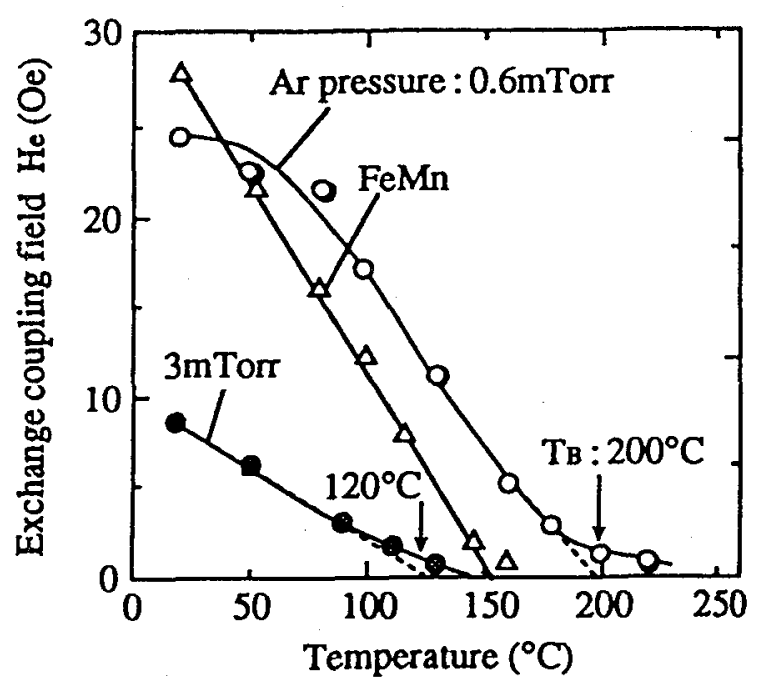

Fig.3 The temperature dependence of the exchange coupling field for bilayered $\mathrm{Ni}_{81} \mathrm{Fe}_{19} / \mathrm{NiO}$ and $\mathrm{FeMn} / \mathrm{Ni}_{81} \mathrm{Fe}_{19}$ films. NiO films were deposited at different argon pressures, 0.6 and 3 mTorr.

shown. Bilayered $\mathrm{Ni}_{81} \mathrm{Fe}_{19} / \mathrm{NiO}$ films in which $\mathrm{NiO}$ was deposited at $3 \mathrm{mTorr}$ exhibit $\mathrm{H}_{\mathrm{e}}$ of $8.7 \mathrm{Oe}$ at room temperature and $T_{B}$ of $120^{\circ} \mathrm{C}$, and these values are not suitable for application to $\mathrm{MR}$ heads. By depositing $\mathrm{NiO}$ films at a low argon pressure of $0.6 \mathrm{mTorr}, \mathrm{H}_{e}$ and $\mathrm{T}_{B}$ increase. In particular, $T_{B}$ shows a reasonably high value of about $200^{\circ} \mathrm{C}$, which is higher than the $150^{\circ} \mathrm{C}$ for FeMn $/ \mathrm{Ni}_{11} \mathrm{Fe}_{19}$.

Figure 4 represents cross-sectional transmission electron microscopy images of NiO films deposited at different argon pressures. The NiO film deposited at a low argon pressure of $0.6 \mathrm{mTorr}$ is composed of larger grains and has a flatter surface than the film deposited at $3 \mathrm{mTorr}$. So it seems that improvement in magnetic properties is attributed to the increase of exchange coupled spins between $\mathrm{Ni}_{81} \mathrm{Fe}_{19}$ and $\mathrm{NiO}$ films.

\section{MR Elements}

As mentioned above, we confirmed that an oxide antiferromagnetic $\mathrm{NiO}$ film exhibits superior corrosion resistance and magnetic properties, so we undertook fabrication of an unshielded MR element using the NiO film. As magnetic properties of $\mathrm{Ni}_{81} \mathrm{Fe}_{19} / \mathrm{NiO}$ are superior to those of $\mathrm{NiO} / \mathrm{Ni}_{81} \mathrm{Fe}_{19}$, and $\mathrm{NiO}$ has high electric resistance, the $\mathrm{NiO}$ film should be placed on opposite sides of the electrode with an MR film placed in between. A schematic structure of a MR element is shown in Figure 5. Exchange coupling between $\mathrm{NiO}$ and MR films is established on both sides of the element, and both films are not in contact at the center of the element in order to allow easy rotation of magnetization in the MR film, thus obtaining high sensitivity. For the transverse biasing method, we used the soft film biasing method. So a spacer and a soft adjacent layer (SAL) were successively fabricated on an MR film.

To examine the effect of exchange coupling between $\mathrm{NiO}$ film and $\mathrm{Ni}_{81} \mathrm{Fe}_{19}$ film only on both sides of the 

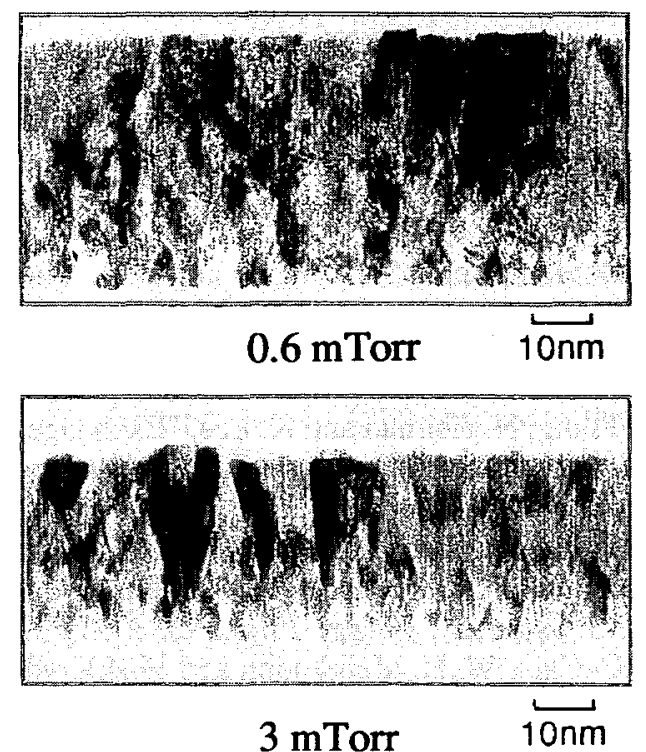

Fig.4 Cross-sectional TEM images of NiO films deposited at different argon pressures.

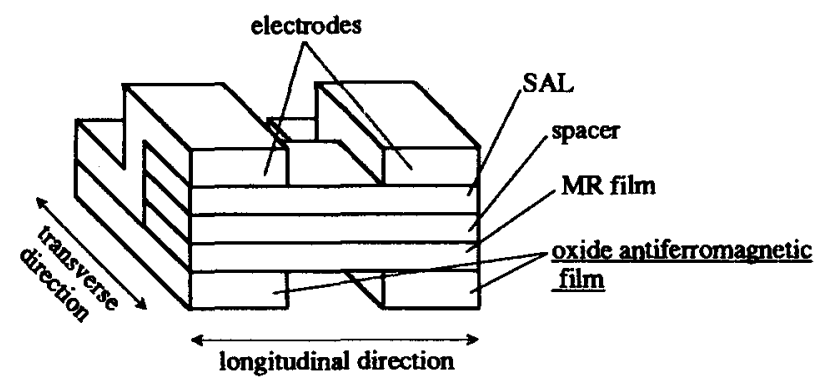

Fig.5 Schematic structure of the MR element.

element, the magnetization pattern in the $\mathrm{Ni}_{81} \mathrm{Fe}_{19}$ film was observed using spin-polarized scanning electron microscopy (spin-SEM). The spin-SEM image shown in Figure 6 indicates that the $\mathrm{Ni}_{81} \mathrm{Fe}_{19}$ film has a single domain state, so we thought that placing $\mathrm{NiO}$ films only on both sides of the MR element can suppress domain wall motion for MR heads.

Figure 7 shows typical MR response for an unshielded MR element. The measurements were carried out with while applying a $50 \mathrm{~Hz}$ transverse maximum field of \pm 300 Oe produced by a Helmholtz coil and supplying a sensing current of $10 \mathrm{~mA}$ with a constant current power supply. No turbulence in MR response was observed except in the region between $\mathrm{H}=+50 \mathrm{Oe}$ and $+100 \mathrm{Oe}$. Because the observed turbulence is not associated with Barkhausen jumps as mentioned below, we considered that Barkhausen jumps are suppressed. The average rotating angle at $\mathrm{H}=0$ of magnetization in the $\mathrm{Ni}_{81} \mathrm{Fe}_{19}$ film from the longitudinal direction can be estimated as about $36^{\circ}$, and at larger sensing currents this value increases by several degrees.

The MR response with two peaks was reported previously, $[13],[14]$ but at their secondary peak the MR

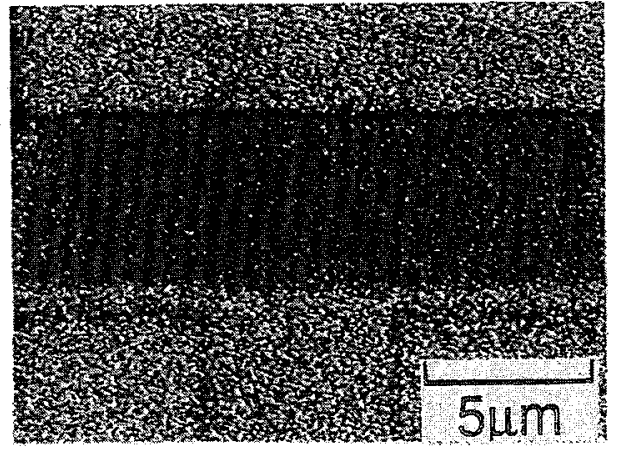

Fig.6 Magnetization pattern, observed with spin-SEM, of the $\mathrm{Ni}_{81} \mathrm{Fe}_{19}$ film, which has exchange coupling with $\mathrm{NiO}$ films on both sides.

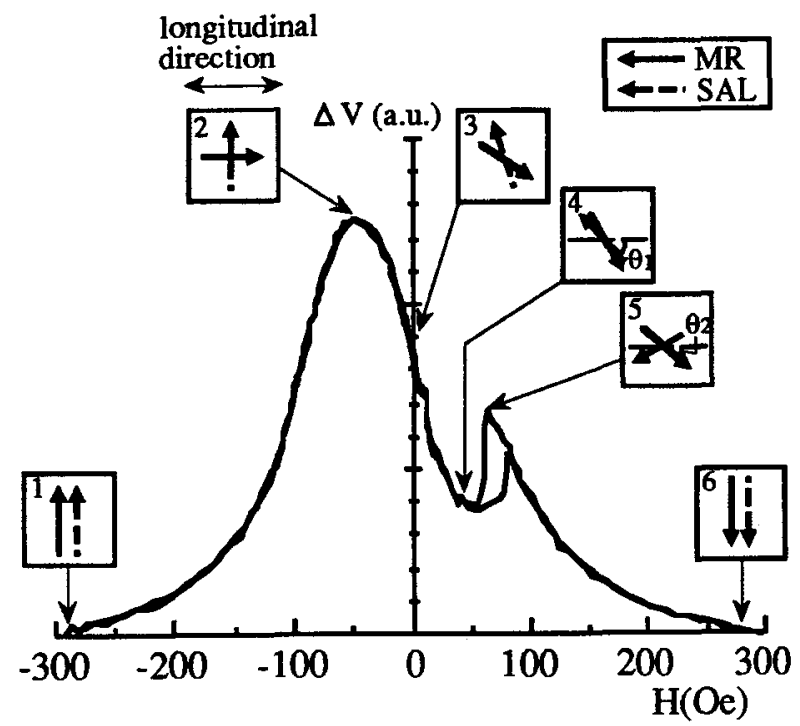

Fig.7 Typical MR response for an unshielded MR element. Schematic movement of magnetization of MR and SAL is also shown.

response changed gradually, not abruptly like the above mentioned turbulence in our MR response. So, we tried to explain the observed turbulence qualitatively. Schematic mutual movement of magnetization in an MR film and SAL is illustrated in Figure 7 . We assumed that both magnetizations orient in the transverse direction of the element at large negative external field (state 1). Only magnetization in the MR film inclines to the longitudinal direction of the element as the external field decreases, and at the peak of $\Delta \mathrm{V}$, both magnetizations are orthogonal (state 2). When $\mathrm{H}=0$, the field acting on the element is only that produced by the sensing current, so they orient in opposite directions to each other with the longitudinal direction between, as illustrated in state 3 . On increasing the positive external field, magnetization in MR inclines to the transverse direction and that in SAL to the longitudinal direction (state 4 ). In the external field which overcomes the field produced by a sensing current, magnetization in SAL suddenly reverses across the transverse direction. And the biasing field acting on the MR film, which is 


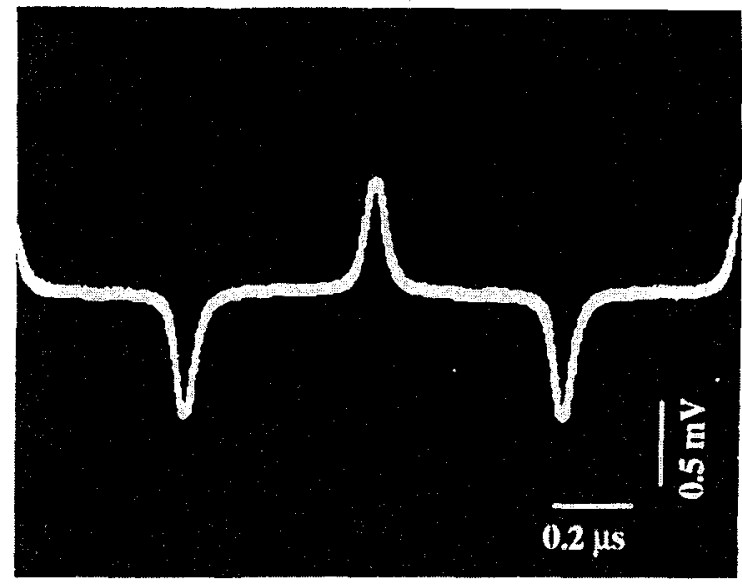

Fig.8 Output waveform a: $5 \mathrm{kFCL}$ for a shielded MR head.

produced by magnetic charges emerging on both edges in the transverse direction of SAL, also reverses, so magnetization in the MR film rotates backward, for example from $\theta_{1}$ (state 4) to $\theta_{2}$ (state 5). Consequently, $\Delta \mathrm{V}$ suddenly increases and turbulence takes place. The difference in response when the positive external field increases and decreases is attributed to the difference in the magnetization distribution. As mentioned above, we considered that the observed turbulence is caused by mutual movement between magnetization in the MR film and SAL.

Figure 8 shows an output waveform at $5 \mathrm{kFCI}$ for a shielded MR head. We observed no distortion associated with Barkhausen jumps, and an excellent property is obtained.

\section{CONCLUSION}

The corrosion resistance of an oxide antiferromagnetic $\mathrm{NiO}$ film and magnetic properties of bilayered $\mathrm{Ni}_{81} \mathrm{Fe}_{19} /$ $\mathrm{NiO}$ films were investigated. We confirmed that the $\mathrm{NiO}$ film has superior corrosion resistance to FeMn and $\mathrm{Ni}_{81} \mathrm{Fe}_{19}$ films, especially under acidic conditions. Bilayered $\mathrm{Ni}_{81} \mathrm{Fe}_{19} / \mathrm{NiO}$ films exhibited good magnetic properties, an exchange coupling field of about $20 \mathrm{Oe}$, and high blocking temperature of about $200{ }^{\circ} \mathrm{C}$. We fabricated an unshielded MR element with $\mathrm{NiO}$ films, which were placed only on both sides of the element in order to obtain high sensitivity. Spin-SEM observations indicated that the $\mathrm{Ni}_{81} \mathrm{Fe}_{19}$ film which had exchange coupling with $\mathrm{NiO}$ films only on both sides exhibited a single domain state. The MR response was measured and no turbulence in the waveform was observed, except within the region between $\mathrm{H}=+50$ Oe and +100 Oe. As the observed turbulence in this region was considered to be associated with a mutual movement between magnetizations of SAL and $\mathrm{Ni}_{81} \mathrm{Fe}_{19}$ film, Barkhausen jumps could be suppressed. Distortion was also not observed in the reproductive waveform for a shielded MR head.

\section{REFERENCES}

[1] C. Tsang and R. Fontana, "Fabrication and Water Testing of Barber-Pole and Exchange-Biased Narrow -Track MR Sensors", IEEE Trans. Magn., - MAG-18, 1149(1982).

[2] R. D. Hempstead, S. Krongelb and D. A. Thomson, "Unidirectional Anisotropy in Nickel-Iron Films by Exchange Coupling with Antiferromagnetic Films", IEEE Trans. Magn., MAG-13, 1466(1977).

[3] C. Tsang, N. Heiman and K. Lee, "Exchange Induced Unidirectional Anisotropy at FeMn-Ni $80 \mathrm{Fe}_{20}$ Interfaces", J. Appl. Phys., 52, 2471(1981).

[4] C. Tsang and K. Lee, "Temperature Dependence of Unidirectional Anisotropy Effects in the PermalloyFeMn Systems", J. Appl. Phys., 53, 2605(1982).

[5] W.C. Cain, W. H. Meiklejohn and M.H.Kryder, "Effects of Temperature on Exchange Coupled Alloys of $\mathrm{Ni}_{80} \mathrm{Fe}_{20}-\mathrm{FeMn}, \mathrm{Ni}_{80} \mathrm{Fe}_{20}-\alpha_{\mathrm{Fe}_{2}} \mathrm{O}_{3}$, and $\mathrm{Ni}_{80} \mathrm{Fe}_{20}$-TbCo", J. Appl. Phys., 61, 4170(1987).

[6] H. Lefakis, T. C. Huang and P. Alexopoulos, "Surface-Oxidation-Induced Phase Separation in FeMn Thin Films", J. Appl. Phys., 64, 5667(1988).

[7] C. Tsang, "Unshielded MR Elements with Patterned Exchange-Biasing", IEEE Trans. Magn., MAG-25, 3692(1989).

[8] M. J. Carey and A. E. Berkowiz, "Exchange Anisotropy in Coupled Films of $\mathrm{Ni}_{81} \mathrm{Fe}_{19}$ with $\mathrm{NiO}$ and $\mathrm{Co}_{\mathrm{x}} \mathrm{Ni}_{1-\mathrm{x}} \mathrm{O}$ ", Appl. Phys. Lett., 60, 3060(1992).

[9] S. Soeya, S. Tadokoro, T. Imagawa, M. Fuyama and S.Narishige, "Magnetic Properties of NiO/NiFe Exchange Coupled Films", Digests of the 15th Conference on Magnetics in Japan, p42,1991.

[10] S. Soeya, S. Tadokoro, T. Imagawa and M. Fuyama, "Magnetic Properties of the Exchange Coupled Permalloy/Low $B_{s}$ Ferromagnetic/Antiferromagnetic films", Digests of the 16th Conference on Magnetics in Japan, p360, 1992.

[11] S. Soeya, S. Tadokoro, T. Imagawa, M. Fuyama and S.Narishige, "Magnetic Exchange Coupling for bilayered $\mathrm{Ni}_{81} \mathrm{Fe}_{19} / \mathrm{NiO}$ and trilayered $\mathrm{Ni}_{81} \mathrm{Fe}_{19} /$ NiFeNb/NiO Films", J. Appl. Phys., 74, 6297(1993).

[12] S. Tadokoro, S. Soeya, T. Imagawa, M. Fuyama and S.Narishige, "Magnetic Properties of Exchange Coupled FeMn/NiFe Films", Digests of the 15th Conference on Magnetics in Japan, p41, 1991.

[13] R. Toussaint, D. Markham and W. Doyle, "Static Characteristics of Soft-Adjacent-Layer Self-Biased Magnetoresistive Heads", IEEE Trans Magn., MAG-22, 677(1986).

[14] S. W. Yuan and H. N. Bartram, "Magnetoresistive Heads for Ultra High Density Recording", IEEE Trans. Magn., MAG-29, 3811(1993). 